NOTES

\title{
Mössbauer Spectroscopic Studies of Complexes of Fe(III) with Nitrogen Containing Polymers
}

\author{
E. A. Bekturov, S. E. Kudaibergenov, G. S. Kanapyanova, \\ S. S. Saltybaeva, A. I. Skushnikova, A. L. Pavlova, \\ and E. S. DomninA* \\ Institute of Chemical Science, Kazakh SSR Academy of Sciences, \\ Alma-Ata 480100, Krasin Str. 106, USSR \\ * Institute of Organic Chemistry Siberian Branch of Academy of Sciences of the USSR, \\ Irkutsk, USSR
}

(Received July 30, 1990)

\author{
KEY WORDS Nitrogen Containing Polymers / Complex Formation / \\ Mössbauer Spectroscopy /
}

Coordination polymer compounds have been successfully used in various catalytic processes such as hydrogenation, oxidation, hydroformylation, polymerization, isomerization, etc. ${ }^{1}$ Nitrogen containing polymers are interesting polymer ligands that function as supports in catalysis.

Complex formation ability of nitrogen containing polymers in relation to the transition metal ions is due to the presence of primary, secondary and tertiary aminogroups which are able to form donor-acceptor bonds. $^{2-7}$ The structures of coordination compounds influence on the catalytic activity of polymer-metal complexes.

In the present paper the results of an investigation of solid complexes of poly(2vinylpyridine) (P2VPy), poly(2-methyl-5-vinylpyridine) (P2M5VPy), poly(4-vinylpyridine) (P4VPy), copolymers of vinylimidazole (VI), and vinylpyrrolidone (VP) with $\mathrm{Fe}(\mathrm{III})$ by Mössbauer and IR spectroscopy are presented in order to elucidate the influence of the polymeric ligand nature on the structures of polymer-metal complexes.

\section{EXPERIMENTAL}

P2VPy, P2M5VPy, and P4VPy were synthesized by the radical polymerization of monomers in methanol at $333 \mathrm{~K}$ in presence of azobisisobutyronitrile (AIBN) as initiator. ${ }^{8}$ Copolymers based on VI and VP were synthesized by radical copolymerization in ethanol at $333 \mathrm{~K}$ in the presence of AIBN. All polymers and copolymers were purified by fractional precipitation. The compositions of copolymers were determined by IR spectroscopy $^{9}$ and by elemental analysis. PVI with molecular weight $16 \times 10^{3}$ and commercial sample of PVP with molecular weight $5.6 \times 10^{5}$ were used.

Intrinsic viscosities of VI-VP copolymers determined in ethanol solution are $0.34,0.43$, and $0.62 \mathrm{dlg}^{-1}$ for $0.63 \mathrm{VI}$ : $0.37 \mathrm{VP} ; 0.41 \mathrm{VI}$ : $0.59 \mathrm{VP}$; and $0.21 \mathrm{VI}$ : $0.79 \mathrm{VP}$, respectively.

The complexes of nitrogen containing polymers with $\mathrm{FeCl}_{3} \cdot 6 \mathrm{H}_{2} \mathrm{O}$ were obtained by mixing the ethanol solutions of the initial components. The precipitated complexes were filtered, washed with ethanol, then dried at room temperature under vacuum.

The Mössbauer spectra of the complexes 


\section{E. A. Bekturov et al.}

were taken with a nucler gamma resonance spectrometer CMTE of an electrodynamic source type at room temperature in the constant acceleration regime. The source of $\gamma$-rays were ${ }^{57} \mathrm{Co}(\mathrm{Pd})$ with an activity of 3 $\mathrm{mCi}$. Absorbers were the complexes of polymers with $\mathrm{Fe}(\mathrm{III})$. The Mössbauer parameters, the isomeric shift $\left(\Delta E_{\mathrm{l}}\right)$ and quadrupole splitting $\left(\delta E_{\mathrm{Q}}\right)$ were calibrated with respect to the standard absorber $\mathrm{Na}_{2}{ }^{57} \mathrm{Fe}(\mathrm{CN})_{5} \mathrm{NO}$.

The Mössbauer parameters were calculated by the computer MERA-60. IR spectra of complexes were obtained with the help of the spectrophotometer "UR-20" (DDR) using
$\mathrm{KCl}$ pellets.

\section{RESULTS AND DISCUSSION}

It was established that during interactions of PVI and VI-VP copolymers with $\mathrm{FeCl}_{3} \cdot 6 \mathrm{H}_{2} \mathrm{O}$ the polymer-metal complexes yield reached $95 \%$. The composition of polymer-metal complexes depends on the molar ratio of initial components and distribution of ligend groups in the case of VI-VP copolymers. Some characteristics of polymer-Fe(III) complexes are shown below.

\begin{tabular}{|c|c|c|c|c|}
\hline Ligand & $\begin{array}{c}\text { Molar ratio } \\
\text { of initial } \\
\text { components } \\
\mathrm{L}: \mathrm{FeCl}_{3}\end{array}$ & $\begin{array}{l}\mathrm{Cl} \% \\
\text { found }\end{array}$ & $\begin{array}{c}\mathrm{Cl} \% \\
\text { calculated }\end{array}$ & $\begin{array}{l}\text { Composition of } \\
\text { complexes }\end{array}$ \\
\hline PVI & $2: 1$ & 22,20 & 22,17 & $(\mathrm{PVI})_{3} \mathrm{FeCl}_{3}$ \\
\hline $0.41 \mathrm{VI}: 0.59 \mathrm{VP}$ & $2: 1$ & 11,93 & 11,74 & $(0.41 \mathrm{VI}: 0.59 \mathrm{VP})_{3} \mathrm{FeCl}_{3}$ \\
\hline $0.63 \mathrm{VI}: 0.37 \mathrm{VP}$ & $2: 1$ & 34,11 & 23,63 & $(0.63 \mathrm{VI}: 0.37 \mathrm{VP})_{2,5} \mathrm{FeCl}_{3}$ \\
\hline
\end{tabular}

The composition of poly(vinylpyridine)Fe(III) complexes does not depend on the molar ratio of initial components, which is equal to $2: 1$.

Complexation of poly(vinylpyridine)s with transition metal ions is often accompanied by the increase of the stretching frequency on the $\mathrm{C}=\mathrm{N}$ bond. ${ }^{10-12}$ This can be used for the elucidation of the complexation ability of polyligands and for the determination of the stability of the coordination compounds.

IR spectra of poly(vinylpyridine) complexes of iron(III) are shown in Figure 1. It is seen that for all complexes $v_{\mathrm{CN}}$ shifted to higher frequency. Analogous shifts are also observed for the out-of-plane vibration of the pyridine ring $\left(v=550 \mathrm{~cm}^{-1}\right) .{ }^{13}$ The complexing ability of poly(vinylpyridine)s in relation to $\mathrm{Fe}$ (III) determined as $\Delta v=v_{\mathrm{CN}}^{\text {coord. }}-v_{\mathrm{CN}}^{\text {free }}$ (where $v_{\mathrm{CN}}^{\text {coord. }}$ and $v_{\mathrm{CN}}^{\text {free }}$ are the frequencies of coordinated and free $\mathrm{CN}$ groups respectively) varies as follows: P2M5VPy $>$ P4VPy $>$ P2VPy.

Mössbauer spectroscopic data of poly- (vinylpyridine) complexes of $\mathrm{Fe}(\mathrm{III})$ are summarized in Table I. The Mössbauer spectra of the complexes represent asymmetric doublets except for P2VPy-Fe(III) which contains only one doublet (Figure 2).

Similar values of isomeric shift and quadrupole splitting for all poly(vinylpyridine) complexes probably indicate similar coordinate

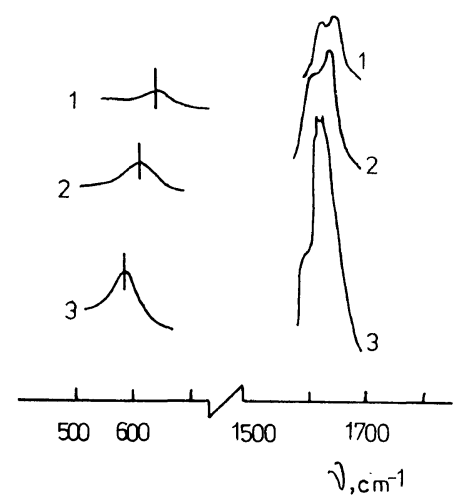

Figure 1. IR spectra of Poly(vinylpyridine) complexes of $\mathrm{Fe}(\mathrm{III})$. 1, P2M5VPy/Fe(III); 2, P4VPy/Fe(III); 3, $\mathrm{P} 2 \mathrm{VPy} / \mathrm{Fe}(\mathrm{III})$. 
Table I. Mössbauer parameters of poly(vinylpyridine) complexes of $\mathrm{Fe}(\mathrm{III})$

\begin{tabular}{|c|c|c|c|}
\hline \multirow{2}{*}{ Poly(vinylpyridine)s } & $\Delta E_{\mathrm{I}}$ & $\delta E_{\mathbf{Q}}$ & $\varepsilon$ \\
\hline & $\mathrm{mm} \mathrm{s}^{-1}$ & $\mathrm{~mm} \mathrm{~s}^{-1}$ & $\%$ \\
\hline \multirow[t]{2}{*}{ P2M5VPy } & 0.34 & 0.51 & \multirow{2}{*}{6.0} \\
\hline & 0.47 & 0.52 & \\
\hline P2VPy & 0.41 & 0.50 & 2.7 \\
\hline \multirow[t]{2}{*}{ P4VPy } & 0.47 & 0.56 & \multirow{2}{*}{1.4} \\
\hline & 0.35 & 0.51 & \\
\hline
\end{tabular}

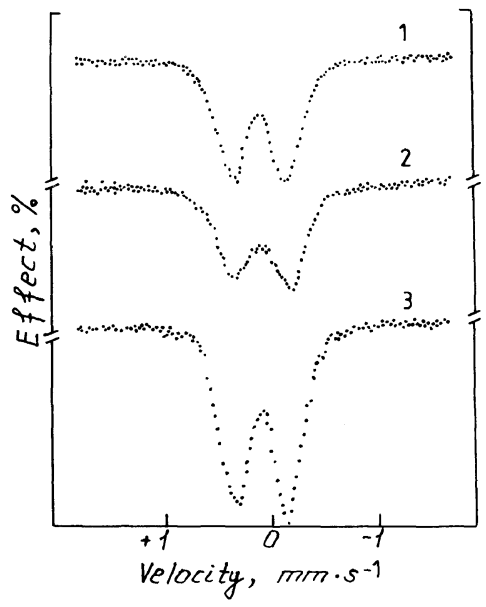

Figure 2. Mössbauer spectra of poly(vinylpyridine) complexes of $\mathrm{Fe}(\mathrm{III}) .1$, P2VPy/Fe(III); 2, P4VPy/Fe(III); 3, P2M5VPy/Fe(III).

surrounding of the irons. The Mössbauer parameters of the complexes are typical of high-spin compounds of $\mathrm{Fe}(\mathrm{III})$. The maximal value of the resonance effect $(\varepsilon)$ for P2M5Py$\mathrm{Fe}$ (III) is accounted for by the formation of a strong coordination bond in this system. This is probably connected with the increase of electron density in the pyridine ring owing to the donor ability of methyl groups.

For iron(III) complexes of VI-VP copolymers the stretching frequency of $\mathrm{C}=\mathrm{C}$ and $\mathrm{C}=\mathrm{N}$ bonds at 1493 and $1503 \mathrm{~cm}^{-1}$ shifted to $1515 \mathrm{~cm}^{-1}$. Spectral changes are also observed for the lactam cycle of VP. The band at $1672 \mathrm{~cm}^{-1}$ corresponding to $\mathrm{C}=\mathrm{O}$ vibrations

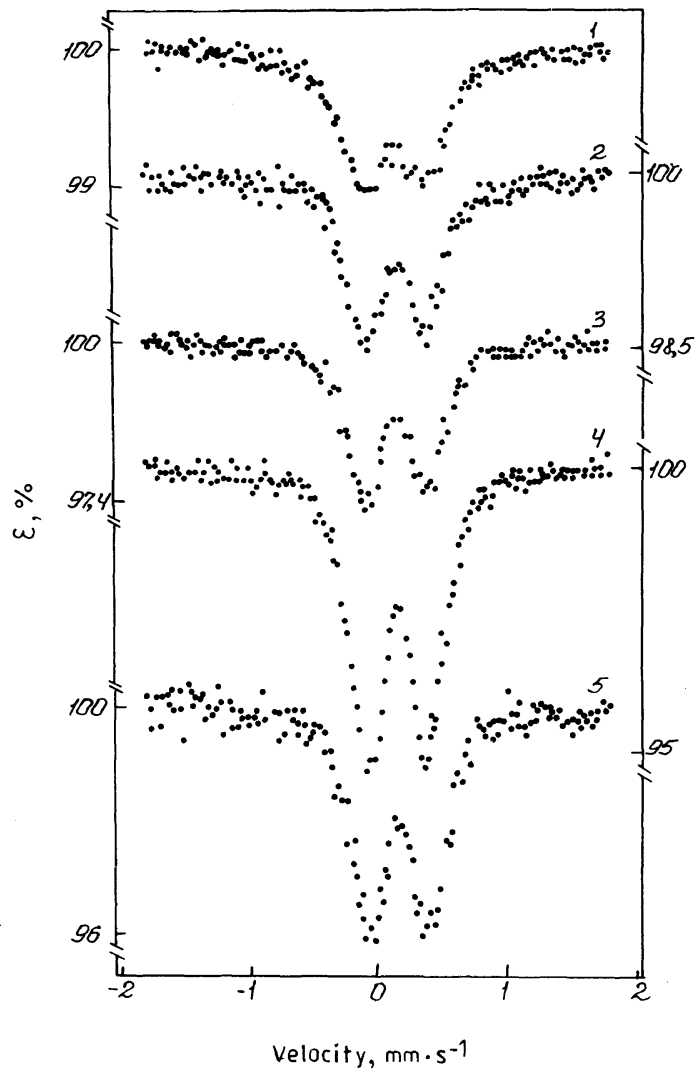

Figure 3. Mössbauer spectra of complexes of $\mathrm{Fe}(\mathrm{III})$ with VI-VP copolymers. 1, PVI/Fe(III); 2, $0.63 \mathrm{VI}: 0.37 \mathrm{VP} /$ $\mathrm{Fe}(\mathrm{III}) ; 3,0.41 \mathrm{VI}: 0.59 \mathrm{VP} / \mathrm{Fe}(\mathrm{III}) ; 4,0.21 \mathrm{VI}: 0.79 \mathrm{VP} /$ $\mathrm{Fe}(\mathrm{III}) ; 5$, PVP/Fe(III).

Table II. Mössbauer parameters of complexes of $\mathrm{Fe}(\mathrm{III})$ with VI-VP copolymers

\begin{tabular}{|c|c|c|c|}
\hline \multirow{2}{*}{ Copolymers } & $\Delta E_{\mathrm{I}}$ & $\delta E_{\mathrm{Q}}$ & $\varepsilon$ \\
\hline & $\mathrm{mm} \mathrm{s}^{-1}$ & $\mathrm{mms}^{-1}$ & $\%$ \\
\hline PVI & 0.50 & 0.67 & 1.0 \\
\hline $0.63 \mathrm{VI}: 0.37 \mathrm{VP}$ & 0.51 & 0.67 & 1.5 \\
\hline $0.41 \mathrm{VI}: 0.59 \mathrm{VP}$ & 0.51 & 0.71 & 2.6 \\
\hline $0.21 \mathrm{VI}: 0.79 \mathrm{VP}$ & 0.54 & 0.66 & 5.0 \\
\hline PVP & 0.55 & 0.66 & 4.0 \\
\hline
\end{tabular}

is shifted to lower frequency at $1630 \mathrm{~cm}^{-1}$. These data indicate the interactions of both nitrogen atoms of the imidazole ring and the carbonyl groups of the lactam cycle with $\mathrm{Fe}(\mathrm{III})$ ions. Earlier ${ }^{2,13}$ it was shown by NMR 
${ }^{13} \mathrm{C}$ and IR spectroscopy that PVP interact with cupric(II) ions only through the carbonyl oxygen of $N$-vinylpyrrolidone groups. Mössbauer spectroscopic data of complexes of $\mathrm{Fe}(\mathrm{III})$ with VI-VP copolymers are presented in Figure 3 and Table II.

As seen from Table II the increase of VP content in copolymers leads to growth of the isomeric shift. From these data the preferential coordination of iron(III) ions with VP units although the nitrogen atom in the VI ring may possibly have more electron donating ability than that of oxygen. This is explained by the fact that the lone pair electrons of nitrogen atoms in VI are conjugated with $\pi$-electrons of the imidazole ring whereas the lone pair electrons of the oxygen atoms in the lactam ring are free and interact more easily with $\mathrm{Fe}(\mathrm{III})$. This is confirmed by the increase in the reasonance effect $(\varepsilon)$.

\section{REFERENCES}

1. E. A. Bekturov and S. Kudaibergenov, "Catalysis by Polymers" (in Russian), Nauka KazSSR, Alma-Ata,
1988, p 181.

2. E. A. Bekturov, S. Kudaibergenov, and R. E. Khamzamulina, Cationic Polymers" (in Russian), Nauka KazSSR, Alma-Ata, 1986, p 160.

3. M. Kaneko and E. Tsuchida, J. Polym. Sci., Macromol. Rev., 16, 397 (1981).

4. E. Tsuchida and H. Nishide, Adv. Polym. Sci., 24, 1 (1977).

5. E. Tsuchida, H. Nishide, H. Yokoyama, J. Inoue, and T. Shirai, Polym. J., 16, 325 (1984).

6. N. Inagaki, R. Suganuma, and K. Katsuura, Eur. Polym. J., 14, 151 (1978).

7. T. D. Z. Atvars, D. N. Dibben, and E. Sabadini, Spectrosc. Lett., 20, 1 (1987).

8. G. M. Lukovkin, O. P. Komarova, V. P. Torchilin, and Yu. E. Kirsh, Vysokomol. Soedin Ser., A15, 443 (1973).

9. G. G. Skvortsova, B. S. Domnina, and A. I. Skushnikova, Vysokomol. Soedin Ser., B, 23, 184 (1981).

10. J. Roda and F. Hrabàk, Makromol. Chém., 177, 1 (1976).

11. J. M. Clear, J. M. Kelly, and J. G. Vos, Makromol. Chem., 184, 613 (1983).

12. A. D. Pomogailo, "Polymer Immobilized Metallocomplex Catalysts" (in Russian), Hauka, Moscow, 1988, p 303.

13. E. A. Bekturov, S. Kudaibergenov, G. S. Kanapyanova, and A. A. Kurmanbaeva, Polym. Commun., 25, 220 (1984). 